CARDIOVASCULAR MEDICINE

\title{
Long term clinical and echocardiographic results of mitral balloon valvotomy in children and adolescents
}

\author{
M E Fawzy, M A Stefadouros, H Hegazy, F El Shaer, M A Chaudhary, F Al Fadley
}

Heart 2005;91:743-748. doi: 10.1136/hrt.2004.040766

See end of article for authors' affiliations

Correspondence to:

Dr Mohamed Eid Fawzy, Department of Cardiovascular Diseases (MBC-16), King Faisal Specialist Hospital \& Research Center, PO Box 3354, Riyadh 11211, Saudi Arabia; robosa@ kfshrc.edu.sa

Accepted 26 August 2004

\begin{abstract}
Aims: To assess the safety, efficacy, and long term results of mitral balloon valvotomy (MBV) for rheumatic mitral stenosis in children and adolescents in comparison to adults.

Methods: The results of 468 patients with mitral stenosis who underwent successful MBV and were followed up for 0.5-13 years were analysed. Patients were divided according to age at the time of MBV into group 1 consisting of 84 patients $\leqslant 20$ years of age (children and adolescents) and group 2 that included 384 patients, age $>20$ (adults).

Results: Patients in group 1 had a lower mitral echo score (mean (SD) 7.5 (1.3) v 8 (1.1), p $<0.001$ ), smaller Doppler mitral valve area (MVA) $\left(0.84(0.17) \vee 0.92(0.18) \mathrm{cm}^{2}, \mathrm{p}<0.001\right)$, and higher Doppler mitral valve gradient (15.0 (5.3) v 12.7 (4.5) $\mathrm{mm} \mathrm{Hg}, \mathrm{p}<0.001$ ) than group 2. Immediately after MBV group 1 had larger MVA, whether measured by Doppler $\left(2.0(0.30) v 1.96(0.28) \mathrm{cm}^{2}\right.$, $\mathrm{p}<0.05)$ or by catheter $\left(2.0(0.59) \vee 1.8(0.52) \mathrm{cm}^{2}, \mathrm{p}<0.001\right)$, and similar complication rates, compared to group 2 . After a mean follow up of 5 (3.5) years there was no significant difference between groups 1 and 2 in the incidence of restenosis (14.3\% v 16.1\%, NS). Event-free survival rates at 5, 10, and 12.5 years were $93 \%, 79 \%$, and $79 \%$ for group 1 and $94 \%, 90 \%$, and $84 \%$ for group 2 ( $p=0.18$ ). Conclusions: MBV is safe and effective in children and adolescents with rheumatic mitral stenosis. It provides better immediate results than in adults and excellent long term results that are comparable to those seen in adults.
\end{abstract}

M itral balloon valvotomy (MBV) is an established nonsurgical modality for the treatment of severe rheumatic mitral valve stenosis. Although in children and adolescents with rheumatic mitral stenosis the immediate haemodynamic effects of MBV have been adequately documented, ${ }^{1-8}$ there are few reports regarding the long term results of MBV in this age group. ${ }^{90}$ The purpose of this study was to evaluate the immediate and long term (up to 13 years) results of MBV in patients 20 years old or younger and compare these results to those obtained in the adult population.

\section{METHODS}

\section{Study population}

From 1989 to 2002, 521 consecutive patients underwent MBV in our hospital. On the basis of immediate results the procedure was successful in 501 (96.2\%) patients and unsuccessful in the remaining 20 patients (severe mitral regurgitation in 10 patients; mitral valve area (MVA) $<1.5 \mathrm{~cm}^{2}$ in 10 patients). These 20 patients were excluded from further analysis. Good immediate results were defined as a post-procedure MVA $\geqslant 1.5 \mathrm{~cm}^{2}$ as assessed by echocardiography and no mitral regurgitation of grade $>2 / 4$ according to the Sellers classification. ${ }^{11}$ Thirty three patients who came from foreign countries were lost to follow up. The remaining 468 (93.4\% of the 501 eligible patients) were followed up for $0.5-13$ years (mean 5 (3.5) years) and constitute the study population. For the purposes of this study patients were divided according to age at the time of MBV into group 1 , age $\leqslant 20$ years (children and adolescents), and group $2>20$ years of age (adults). Written informed consent was obtained from all patients or, in the case of patients under legal age, from their parents or guardians, before MBV.

\section{Echocardiographic and Doppler examination}

Two dimensional (2D echo) and Doppler echocardiographic studies were performed 1-2 weeks before the procedure using commercially available equipment (Hewlett-Packard Unit Sonos 1500 and 5500). In addition to the mean transmitral valve gradient, the MVA was calculated from the Doppler study using the pressure half-time method $^{12}$ and also by planimetry using the short axis 2D echo view. Pulmonary artery systolic pressure was estimated by continuous wave Doppler echocardiography using the modified Bernoulli

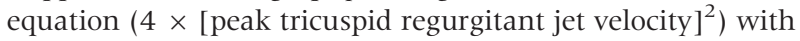
$10 \mathrm{~mm} \mathrm{Hg}$ added for the estimated right atrial pressure. ${ }^{13}$ The echo Doppler studies were repeated immediately after MBV, at six months, and annually thereafter for up to 13 years. The morphologic features of the mitral valve were categorised according to semiquantitated grading of leaflet thickening, mobility, calcification, and subvalvar involvement on a scale of 0 to 4 as described. ${ }^{14}$ The mitral valve morphology was considered favourable if the mitral echocardiographic score (MES) was $\leqslant 8$.

\section{Mitral balloon valvotomy procedure}

Mitral balloon valvotomy was performed according to the stepwise Inoue technique as previously described. ${ }^{15}{ }^{16}$ Standard haemodynamic measurements of the right and left heart included simultaneous measurement of left atrial and left ventricular pressures, mean mitral gradient, and MVA calculated using the Gorlin's formula. Cardiac output was determined by the Fick or themodilution method. All haemodynamic measurements were obtained before and immediately after MBV. A computer (Micro-Siemens

Abbreviations: $M B V$, mitral balloon valvotomy; MES, mitral echocardiographic score; MVA, mitral valve area; NYHA, New York Heart Assocation 


\begin{tabular}{|c|c|c|c|}
\hline & $\begin{array}{l}\text { Group } 1 \\
\text { (age } \leqslant 20 \text { ) }\end{array}$ & $\begin{array}{l}\text { Group } 2 \\
\text { (age }>20 \text { ) }\end{array}$ & $\begin{array}{l}\text { p Value } \\
\text { (group I v II) }\end{array}$ \\
\hline Number of patients & 84 & 384 & \\
\hline Sex (male) & $29(34.5 \%)$ & $99(25.8 \%)$ & NS \\
\hline Age (years) & $16.7(3.3)$ & $33.7(9.5)$ & $<0.0001$ \\
\hline Age range (years) & $10-20$ & $21-61$ & \\
\hline Weight (kg) & $45(10)$ & $62(18)$ & $<0.001$ \\
\hline Range & $20-68$ & $46-85$ & \\
\hline Body surface area $\left(\mathrm{m}^{2}\right)$ & $1.4(0.17)$ & $1.6(0.24)$ & $<0.01$ \\
\hline Atrial fibrillation & $6(7.1 \%)$ & $58(15.1 \%)$ & 0.05 \\
\hline NYHA class III/IV & 76 (90.4\%) & $337(87.8 \%)$ & NS \\
\hline Mitral echo score & $7.5(1.3)$ & $8(1.1)$ & $<0.001$ \\
\hline Previous surgical & & & \\
\hline commissurotomy & $2(2.4 \%)$ & $17(4.4 \%)$ & NS \\
\hline Mitral regurgitation (grade 1) & $18(21.4 \%)$ & $127(33.1 \%)$ & 0.05 \\
\hline
\end{tabular}

Elema-AB, Solna, Sweden) was used for the calculation of haemodynamic parameters. Left ventriculography was performed before and immediately after valvotomy in order to assess the presence and severity of mitral regurgitation using the Sellers classification. ${ }^{11}$

\section{Follow up}

Clinical and echocardiographic assessments were carried out six months after MBV and annually thereafter for up to 13 years. The primary end point of follow up was mitral restenosis, defined as loss of $\geqslant 50 \%$ of the initial gain in MVA and MVA $<1.5 \mathrm{~cm}^{2}$. The combined secondary end point included: (1) mitral restenosis (as defined above); (2) redo MBV; (3) mitral valve replacement; (4) New York Heart Association (NYHA) functional class III or IV; (5) cardiac death. Follow up evaluation at regular intervals consisted of direct interview with and physical examination of the patient, in addition to echocardiographic examination at each clinic visit. For prophylaxis against recurrence of rheumatic fever, patients were given either monthly intramuscular injections of benzanthine penicillin G 1.2 MU (or half this dose for children with body weight of $\leqslant 27 \mathrm{~kg}$ ) or oral penicillin V $250 \mathrm{mg}$ twice daily. For patients allergic to penicillin, erythromycin (250 mg orally twice daily) was given instead. This prophylactic treatment was continued at least until age of 35 years.

\section{Statistical analysis}

Statistical analysis was performed using a commercially available software package (SAS v.8; Statistical Analysis
System, SAS Institute Inc, Cary, North Carolina, USA). Invasive and echocardiographic data obtained before, immediately after, and long term after valvotomy in group 1 were compared with the corresponding data in group 2 using the non-paired Student's $t$ test (two tailed) or the $\chi^{2}$ test (two tailed) or the Fisher's exact test, as appropriate. The overtime change from baseline to follow up was evaluated separately for each age group by the paired Student's $t$ test. Univariate Cox regression analysis was used to identify predictors of restenosis. Kaplan-Meier analysis was used to determine (1) freedom from restenosis, and (2) event-free survival (survival with freedom from the predefined combined end points listed above) for patients in the two age groups. Comparison between groups was performed using the log rank test. Descriptive statistics for the continuous variables are reported as mean (SD). The level of significance was set at $\mathrm{p}<0.05$.

\section{RESULTS}

Demographic characteristics of both groups of patients are shown in table 1 . The age in group 1 ranged from 10-20 years (mean (SD) 16.7 (3.3) years) and in group 2 from 21-61 years (mean 33.7 (9.5) years). Their weight range from 20-68 kg (mean 45 (10) kg for group 1 and 62 (18) kg for group 2, $\mathrm{p}<0.001)$. The mean body surface area (BSA) was 1.4 $(0.17) \mathrm{m}^{2}$ for group $\mathrm{l}$ and $1.6 \quad(0.24) \mathrm{m}^{2}$ for group 2 $(\mathrm{p}<0.01)$. Although male sex represented the minority in group $1(29 / 84 ; 34.5 \%)$ and group 2 (99/384; $25.8 \%)$, there was no significant difference between the two groups in sex distribution $(\mathrm{p}=0.104)$. The prevalence of atrial fibrillation was lower in the younger group $1(6 / 84 ; 7.1 \%)$ than in the adult group $2(58 / 384 ; 15.1 \%)(p=0.05)$. The echocardiographic mitral valve score was slightly lower in group 1 than in group 2 (7.5 (1.3) $\vee 8$ (1.1); p $<0.001)$.

Table 3 Baseline and immediate Doppler haemodynamic results

\begin{tabular}{lllll}
\hline Parameter & $\begin{array}{l}\text { Group 1 } \\
(\mathbf{n}=84)\end{array}$ & $\begin{array}{l}\text { Group 2 } \\
(\mathbf{n}=384)\end{array}$ & $\begin{array}{l}\text { p Value } \\
\text { (group 1 v 2) }\end{array}$ \\
\hline Doppler MG (mm Hg) & B & $15(5.3)$ & $12.7(4.5)$ & $<0.001$ \\
& I & $5(1.8)^{*}$ & $5(1.78)^{*}$ & $\mathrm{NS}$ \\
Doppler MVA $\left(\mathrm{cm}^{2}\right)$ & B & $0.84(0.17)$ & $0.92(0.18)$ & $<0.001$ \\
& I & $2.0(0.30)^{*}$ & $1.96(0.28)^{*}$ & $<0.05$ \\
\hline
\end{tabular}

${ }^{*} \mathrm{p}<0.0001$ in comparison with baseline values in the same group. $B$, before valvotomy; I, immediately after valvotomy; $M G$, mean transmitral valve gradient; MVA, mitral valve area; NS, non-significant difference.

Table 2 Baseline and immediate catheter haemodynamic results

\begin{tabular}{|c|c|c|c|c|}
\hline Parameter & & Group $1(n=84)$ & Group 2 ( $n=384)$ & $\begin{array}{l}\text { p Value } \\
\text { (group } 1 \text { v 2) }\end{array}$ \\
\hline \multirow[t]{2}{*}{ Mean mitral gradient $(\mathrm{mm} \mathrm{Hg})$} & B & $17(4.7)$ & $15.4(4.9)$ & 0.006 \\
\hline & I & $5.2(2.2)^{\star \star *}$ & $5.4(2.5)^{\star \star *}$ & NS \\
\hline \multirow[t]{2}{*}{ MVA $\left(\mathrm{cm}^{2}\right)$} & B & $0.84(0.24)$ & $0.83(0.24)$ & NS \\
\hline & I & $2.0(0.59)^{* \star *}$ & $1.8(0.52)^{\star * *}$ & $<0.001$ \\
\hline \multirow[t]{2}{*}{ Mean LA pressure $(\mathrm{mmHg})$} & B & $26(5.3)$ & $24.8(5.9)$ & NS \\
\hline & I & $14.6(3.6)^{* * *}$ & $14.8(4.4)^{\star * *}$ & NS \\
\hline \multirow[t]{2}{*}{ Systolic PAP (mm Hg) } & B & $48.0(16.2)$ & $48.5(17)$ & NS \\
\hline & I & $38.3(14.5)^{* * *}$ & $39.2(14.3)^{\star * *}$ & NS \\
\hline \multirow[t]{2}{*}{ PVR (dynes $/ \mathrm{s} / \mathrm{cm}^{5}$ ) } & B & $232(237)$ & $258(230)$ & NS \\
\hline & I & $227(172) \dagger$ & $241(216)^{*}$ & NS \\
\hline \multirow[t]{2}{*}{ Cardiac index $\left(1 / \mathrm{min} / \mathrm{m}^{2}\right)$} & B & $3.0(0.74)$ & $2.43(0.63)$ & $<0.0001$ \\
\hline & I & $3.4(0.97)^{\star *}$ & $2.8(1.3)^{\star * *}$ & $<0.0001$ \\
\hline
\end{tabular}


Table 4 Procedure related complications

\begin{tabular}{|c|c|c|c|}
\hline & $\begin{array}{l}\text { Group } 1 \\
(n=84)\end{array}$ & $\begin{array}{l}\text { Group } 2 \\
(n=384)\end{array}$ & $\begin{array}{l}\text { p Value } \\
\text { (group } 1 \text { v 2) }\end{array}$ \\
\hline Procedure related death & 0 & 0 & NS \\
\hline $\begin{array}{l}\text { Cardiac tamponade } \\
\text { Severe post-procedure }\end{array}$ & $1(1.2 \%)$ & $4(1.04 \%)$ & NS \\
\hline$(M R \geqslant 3)$ & 0 & $10^{*}$ & NS \\
\hline In-hospital MVR & 0 & $5^{*}$ & NS \\
\hline Cerebral TE events & 0 & $3(0.8 \%)$ & NS \\
\hline Stroke & 0 & $2(0.5 \%)$ & NS \\
\hline latrogenic atrial septal defect & $17(20.2 \%)$ & $103(26.8 \%)$ & NS \\
\hline
\end{tabular}

*These patients were excluded from the follow up study $M R$, mitral regurgitation; MVR, mitral valve replacement; NS, nonsignificant difference; TE, thomboembolic.

\section{Immediate haemodynamic results}

Balloon valvotomy resulted in a significant, immediate increase in MVA with a corresponding significant decrease in transmitral gradient, whether measured invasively (table 2) or by Doppler echocardiography (table 3), in both groups. In addition, a substantial fall in catheter measured mean left atrial pressure and systolic pulmonary artery pressure, with an associated increase in cardiac index, were noted in both groups immediately after MBV. The statistical comparison of haemodynamic and echocardiographic data obtained before and immediately after valvotomy between the two groups is shown in tables 2 and 3. Although at baseline there was a small difference in Doppler MVA between group 1 and group $2 \quad(0.84 \quad(0.17) \quad v \quad 0.92$ $(0.18) \mathrm{cm}^{2}$, respectively; $\left.\mathrm{p}<0.001\right)$, both groups had the same MVA calculated by catheterisation $(0.84(0.24) v 0.83$ $(0.24) \mathrm{cm}^{2}$; NS). Immediately after valvotomy the MVA was larger in group 1 than in group 2, whether measured by catheter $\left(2.0(0.59) \quad v \quad 1.8(0.52) \mathrm{cm}^{2} ; \mathrm{p}<0.001\right)$ or by Doppler $\left(2.0(0.30) v 1.96(0.28) \mathrm{cm}^{2} ; \mathrm{p}<0.05\right)$ (tables 2 and $3)$. There were no significant differences between the two groups in invasively determined mean left atrial pressure, systolic pulmonary arterial pressure, or pulmonary vascular resistance both before and immediately after valvotomy (table 2).

\section{Complications}

The incidence of major adverse in-hospital events is shown in table 4. There were no in-hospital deaths. As noted above, severe post-valvotomy mitral regurgitation (grade $\geqslant 3$ ) occurred in $10 / 521$ patients $(1.9 \%)$; all 10 patients were adults, nine of whom had significant subvalvar fusion. Five of the 10 patients with severe mitral regurgitation underwent

\begin{tabular}{|c|c|c|c|c|}
\hline Parameter & & $\begin{array}{l}\text { Group } 1 \\
(n=84)\end{array}$ & $\begin{array}{l}\text { Group } 2 \\
(\mathrm{n}=384)\end{array}$ & $\begin{array}{l}\text { p Value } \\
\text { (group 1 v 2) }\end{array}$ \\
\hline Doppler MG (mm Hg) & $B$ & $15(5.3)$ & $\begin{array}{l}12.7(4.5) \\
5.8(27)^{*}\end{array}$ & $\begin{array}{l}<0.001 \\
N S\end{array}$ \\
\hline \multirow[t]{2}{*}{ Doppler MVA $\left(\mathrm{cm}^{2}\right)$} & B & $\begin{array}{l}5.4(2.2) \uparrow \\
0.84(0.17)\end{array}$ & $0.92(0.18)$ & $<0.001$ \\
\hline & $\mathrm{F}$ & $1.8(0.34)^{* *}$ & $1.7(0.37)^{* *}$ & NS \\
\hline \multirow[t]{2}{*}{ Systolic PAP (mm Hg) } & B & $47.5(16.2)$ & $46.9(18)$ & NS \\
\hline & $\mathrm{F}$ & $28(4.7)^{* *}$ & $31(9.9)^{* *}$ & NS \\
\hline \multirow[t]{2}{*}{ LA dimension $(\mathrm{mm})$} & B & $46(9)$ & $48.5(6.9)$ & $<0.01$ \\
\hline & $\mathrm{F}$ & $44(6.5)^{* *}$ & $44(7.3)^{* *}$ & NS \\
\hline Restenosis & & 12 (14.3\%) & $62(16.1 \%)$ & NS \\
\hline
\end{tabular}

${ }^{*} p<0.001 ;{ }^{* *} p<0.0001 ; \mathrm{t} p=$ NS (all in comparison to baseline values in the same group).

$B$, before valvotomy; $F$, follow up; LA, left atrial; $M G$, transmitral valve gradient; MVA, mitral valve area; NS, non-significant difference; PAP, pulmonary arterial pressure. mitral valve replacement during their hospitalisation. Pericardial tamponade occurred in four patients in the adult group ( $1 \%)$ and one patient $(1.2 \%)$ in the young group. Atrial septal defect was detected by colour flow mapping immediately after MBV in 17 patients $(20.2 \%)$ in the young group and in 103 patients $(26.8 \%)$ in the adult group. Cerebral thromboembolic events occurred in three patients $(0.8 \%)$, all of them from the adult group; one of these patients recovered completely and two patients developed stroke. The differences between the two groups in the incidence of all these complications were insignificant (table 4).

\section{Follow up results}

Echocardiographic assessment performed after a follow up period of 0.5-13 years (mean 5 (3.5) years) demonstrated an MVA of $1.8(0.34) \mathrm{m}^{2}$ and $1.7(0.37) \mathrm{m}^{2}$ for group 1 and 2 , respectively (NS). The mean diastolic mitral valve gradient remained at 5.4 (2.2) $\mathrm{mm} \mathrm{Hg}$ and 5.8 (2.7) $\mathrm{mm} \mathrm{Hg}$, respectively (NS). Left atrial enlargement, as determined by the echocardiographic anteroposterior left atrial dimension, was present at baseline in both groups, although less pronounced in group 1 (46 (9) $v 48.5$ (6.9); p < 0.01). A significant reduction in left atrial dimension was observed at follow up in both groups (44 (6.5) $\mathrm{mm} v 44(7.3) \mathrm{mm}$ for groups $\mathrm{I}$ and 2 , respectively; NS) (table 5 ).

\section{Restenosis}

Restenosis was encountered in 12 patients (14.3\%) of group 1 , nine of whom had successful redo MBV. Restenosis was also observed in 62 patients (16.1\%) of group 2, 26 of whom underwent repeat MBV and 11 had mitral valve replacement. The remaining 28 patients with restenosis (three of group 1 and 25 of group 2) were either asymptomatic or mildly symptomatic and therefore did not require reintervention. No statistical difference was found in the incidence of restenosis between the two groups (table 5). Univariate Cox regression analysis identified mitral echocardiographic score as the only significant predictor of mitral valve restenosis $(p<0.0001)$. The estimated restenosis-free survival for the whole population and for patients with MES $\leqslant 8$ and MES $>8$ is depicted in fig 1 . The restenosis rate is much higher in patients with MES $>8(p<0.0001)$ while fig 2 shows that freedom from restenosis was not different between the two age groups.

\section{Follow up events}

In group 1 , no deaths occurred at follow up. Nine patients in this group $(10.7 \%)$ had redo MBV because of restenosis associated with severe symptoms (NYHA class III/IV). The remaining 75 patients $(89.3 \%)$ remained in functional class I/II.

In group 2, one patient with end stage renal failure died at follow up after mitral valve replacement for mitral restenosis. A total of $37 / 384$ patients $(9.6 \%)$ of this group were submitted to either redo MBV (26 patients; $6.8 \%$ ) or mitral valve replacement (11 patients; $2.8 \%$ ) because of severely symptomatic restenosis. The remaining 346 patients in this group were mildly symptomatic (NYHA class I/II) without further cardiac intervention. The probability of event-free survival at 5, 10, and 12.5 years were $93 \%, 79 \%$, and $79 \%$ for group 1 versus $94 \%, 90 \%$, and $84 \%$ for group 2 , respectively $(\mathrm{p}=0.18)$ (fig 3).

No patients in either group developed symptoms suggestive of recurrent rheumatic fever during follow up.

\section{Regression of pulmonary hypertension}

Comparison of values for systolic pulmonary artery pressure obtained by Doppler before valvotomy to those seen at follow up demonstrated a significant regression of pulmonary hypertension over time in both groups. Thus, in group 1 the 


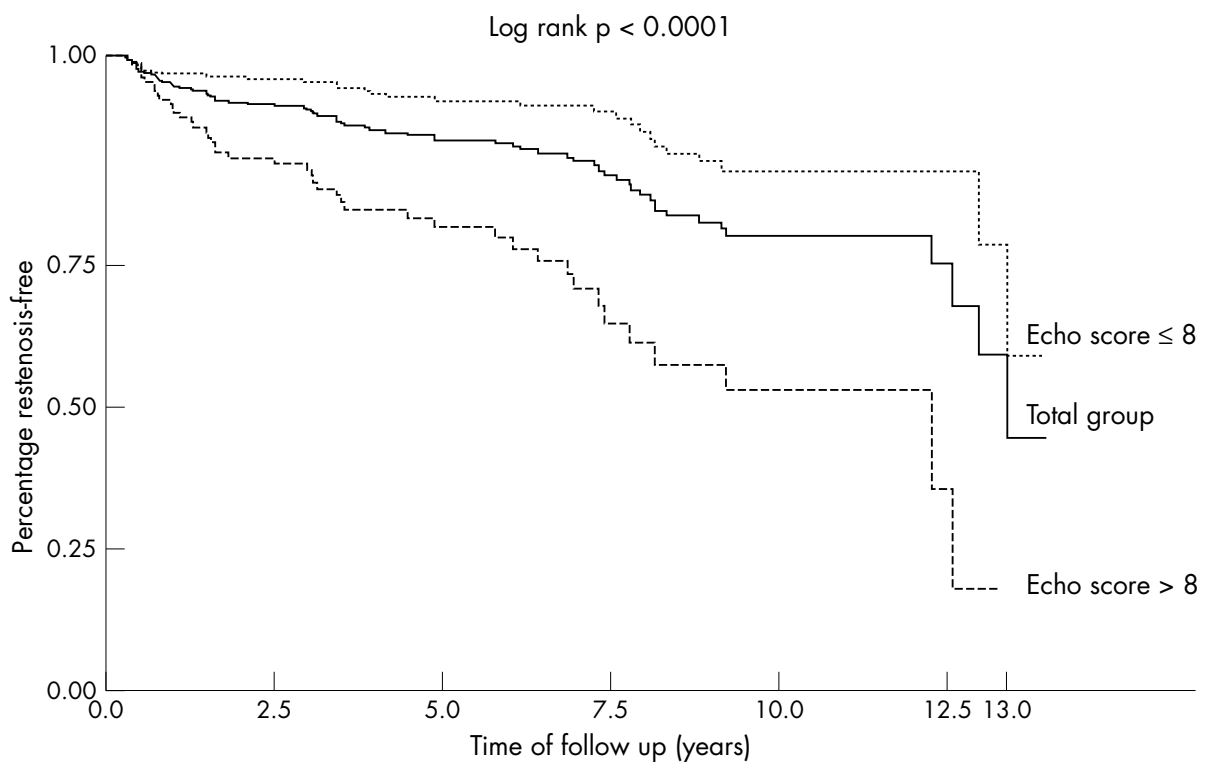

Figure 1 Freedom from restenosis by Kaplan-Meier analysis for the whole group and patients with mitral echocardiographic score (MES) $\leqslant 8$ and patients with MES $>8$.

systolic pulmonary artery pressure fell from 47.5 (16.2) $\mathrm{mm} \mathrm{Hg}$ before MBV to 28 (4.7) $\mathrm{mm} \mathrm{Hg}$ at follow up $(\mathrm{p}<0.0001)$. The corresponding values for systolic pulmonary artery pressure in group 2 (before: 46.9 (18) $\mathrm{mm} \mathrm{Hg}$, follow up: $31(9.9 \mathrm{~mm} \mathrm{Hg}$; p $<0.0001)$ were not significantly different from those observed in group 1. Most of this reduction in systolic pulmonary artery pressure occurred over time as demonstrated by Doppler echocardiography (table 5) following the initial modest drop observed by catheterisation recording immediately after the procedure (table 2 ).

\section{Atrial septal defect}

Immediately after MBV, iatrogenic atrial septal defect with small left to right shunt at the atrial level was detected by colour flow mapping in 17 patients in group $1(20.2 \%)$ and 103 patients $(26.8 \%)$ of group 2 . The majority of these defects were closed at 4-12 months after valvotomy. At long term follow up, these defects were closed in all patients in group 1 and in all but nine patients in group 2 .

\section{DISCUSSION}

Several studies have described the salutary immediate and mid term haemodynamic results of balloon valvotomy in children and adolescents with mitral valve stenosis. ${ }^{1-8}$ However, long term follow up studies of MBV in children are scarce. ${ }^{9}{ }^{10}$ This study provides a longer follow up period compared to other studies. ${ }^{9}{ }^{10}$ Pericardial tamponade, cerebral embolisation, and significant mitral regurgitation, are recognised complications of balloon mitral valvotomy. The rate of these complications in our series was lower than that previously reported by others. ${ }^{101718}$

\section{Immediate results}

The immediate results of MBV in our young age group were slightly better than those seen the adult group with a significantly larger immediate MVA in spite of a smaller BSA. This difference is probably related to the more favourable mitral valve morphology in the young as demonstrated by their lower mitral echocardiographic score. These findings are comparable to those reported by others. ${ }^{256910}$

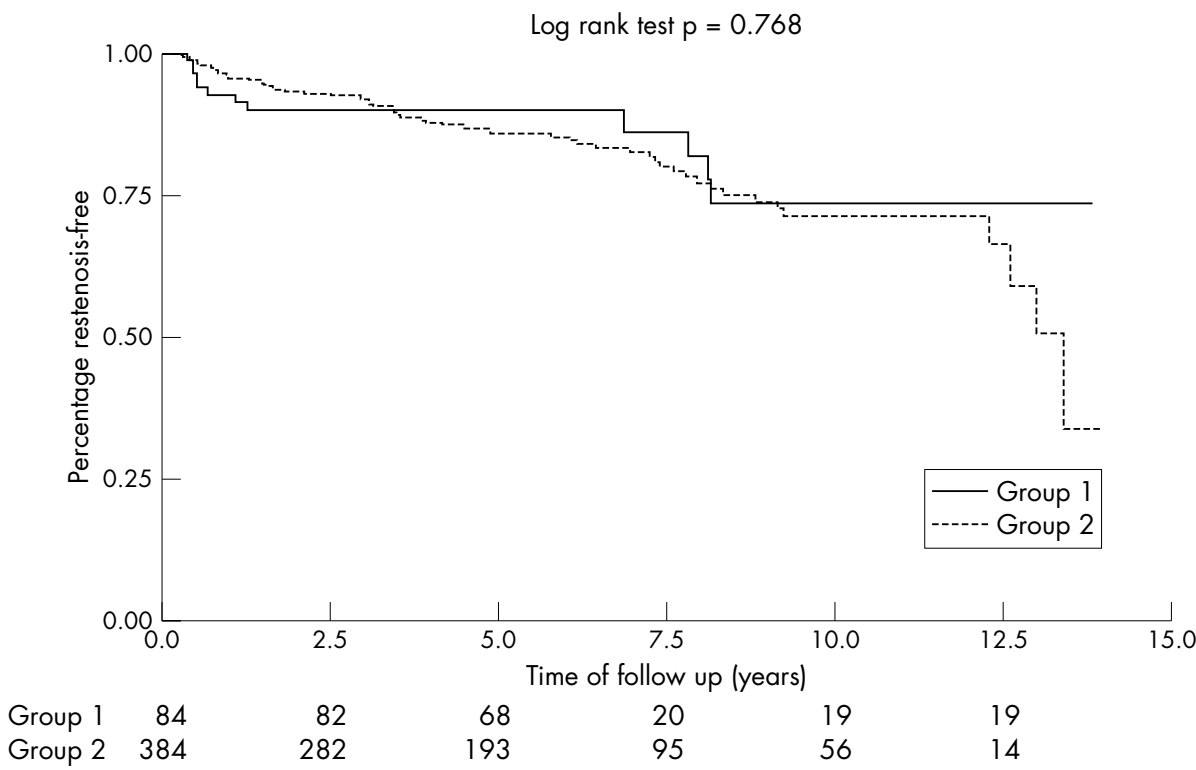

Figure 2 Freedom from restenosis by Kaplan-Meier analysis in both groups at $2.5,5,7.5,10$, and 12.5 years of follow up. 


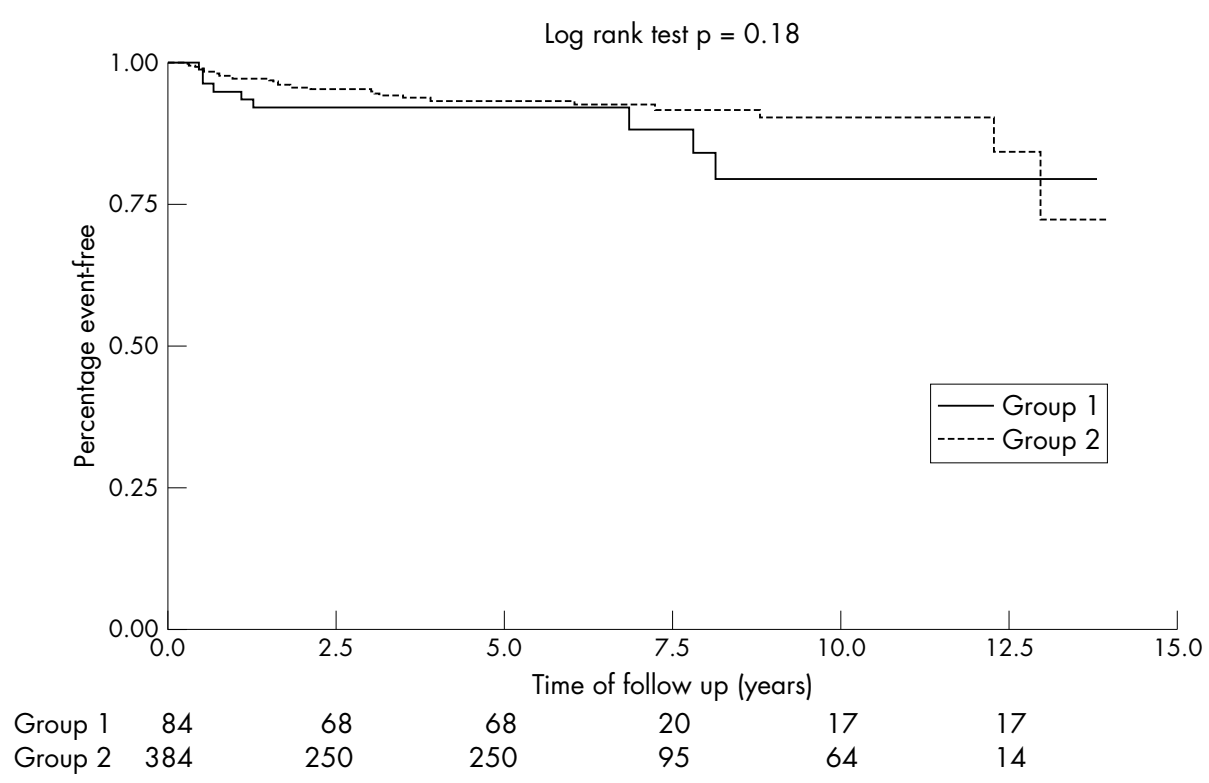

Figure 3 Event-free survival by Kaplan-Meier analysis in both groups at $2.5,5,7.5,10$, and 12.5 years of follow up.

\section{Long term results}

Mitral restenosis

It has been hypothesised that children and adolescent patients may be more prone to developing restenosis because of the increased likelihood of smouldering rheumatic activity or recurrence of rheumatic fever in this age group. This hypothesis is not supported in our series where the restenosis rate was similar in the two age groups and no rheumatic fever recurrences were noted. The results of this study indicate that the valve morphology rather than the patient's age is the main determinant of valve restenosis. These findings concur with reports of other investigators. ${ }^{10}{ }^{19-23}$ Although no link was established between restenosis and recurrent rheumatic fever in our population, the absence of instances of recurrence of rheumatic fever confirms the effectiveness of long-term prophylactic antibiotic treatment.

\section{Event-free survival}

Although the difference in clinical events between the two groups failed to reach significance, there was a trend towards fewer events in the young population, most likely related to lower incidence of atrial fibrillation and more favourable mitral valve morphology in this young group. Kaplan-Meier analysis showed that $93 \%$ and $79 \%$ of the young population versus $94 \%$ and $84 \%$ of the adult population were alive and free from clinical events at 5 and 12.5 years of follow up, respectively, a finding corroborated by other investigators. ${ }^{9} 10$ This lack of intergroup difference in survival and adverse long term clinical events could possibly be attributed to the fact that our adult population was relatively young (mean age 33.7 (9.5) years), a finding similar to that reported by other investigators. ${ }^{10}$

\section{Regression of pulmonary hypertension}

As previously reported by us ${ }^{1}$ and others, ${ }^{524}$ severe pulmonary hypertension is present in a large proportion of children with mitral valve stenosis. Immediately following valvotomy, pulmonary hypertension decreases slightly, with further substantial regression occurring at long term follow up, a finding consistent with the results of previously reported studies. ${ }^{25} 26$

Atrial septal defect

The reported incidence of an atrial septal defect following MBV has ranged from 9-53\%, with most defects closing after
3-12 months. ${ }^{27-29}$ The incidence of iatrogenic atrial septal defect in our population was within this range and its distribution was similar in both groups. At follow up, 92.5\% (111/120) of such defects were closed.

\section{Conclusions}

Mitral balloon valvotomy is safe and effective in children and adolescents with rheumatic mitral stenosis. The immediate results of this procedure are slightly better in this young age group than in adults, with excellent long term results comparable to those seen in adult patients.

\section{ACKNOWLEDGEMENTS}

We would like to thank Ms Lydia Robosa for her secretarial assistance.

\section{Authors' affiliations}

M E Fawzy, M A Stefadouros, H Hegazy, F E Shaer, F A Fadley, Department of Cardiovascular Diseases and the Department of Biostatistics, Epidemiology, King Faisal Specialist Hospital and Research Center Riyadh, Saudi Arabia

M A Chaudhary, Department of Cardiovascular Diseases and the Department of Scientific Computing, King Faisal Specialist Hospital and Research Center Riyadh, Saudi Arabia

\section{REFERENCES}

1 Fawzy ME, Mimish L, Awad M, et al. Mitral balloon valvotomy in children with Inove technique: immediate and intermediate term results. Am Heart $J$ 1994; 127:1559-62.

2 Bahl VK, Chandra S, Kothari SS, et al. Percutaneous transvenous mitral commissurotomy using Inoue catheter in juvenile rheumatic mitral stenosis. Cathet Cardiovasc Diagn 1994; (suppl 2):82-6.

3 Joseph PK, Bhat A, Francis B, et al. Percutaneous transvenous mitral commissurotomy using an Inoue balloon in children with rheumatic mitral stenosis. Int J Cardiol 1997;62:19-22.

4 Shrivastava S, Chandra YV, Krishnamoorthy KM, et al. Mitral valvotomy with the Inoue balloon in juvenile rheumatic mitral stenosis. Am J Cardiol 1995;76:404-6.

5 Sinha N, Kapoor A, Sreenivas K, et al. Immediate and follow up results of Inoue balloon mitral valvotomy in juvenile rheumatic mitral stenosis. J Heart Valve Dis 1997;6:599-603.

6 Essop MR, Govendrageloo K, Du Plessis J, et al. Balloon mitral valvotomy for rheumatic mitral stenosis in children aged $\leqslant 12$ years. Am J Cardiol 1993;72:850-1.

7 Kothari SS, Kamath P, Juneja R, et al. Percutaneous transvenous mitral commissurotomy using Inoue balloon in children less than 12 years. Cathet Cardiov Diag 1998;43:408-11.

8 Mattos C, Braga SL, Esteves CA, et al. Percutaneous mitral valvotomy in patients eighteen years old and younger. Immediate and late results. Arquivos Brasileiros de Cardiologia 1999;73:373-81. 
9 Zaki A, Salama M, El Masry M, et al. Five-year follow-up after percutaneous balloon mitral valvuloplasty in children and adolescents. Am J Cardiol 1999;83:735-9.

10 Gamra H, Betbout F, Ben Hamda K, et al. Balloon mitral commissurotomy in juvenile rheumatic mitral stenosis: a ten-year clinical and echocardiographic actuarial results. European Heart J 2003;24:1349-56.

11 Sellers RD, Levy M J, Amplitz R, et al. Retrograde angiography in acquired cardiac diseases: technique, indications and interpretation in 700 cases: $\mathrm{Am} J$ Cardiol 1964:14:437-47.

12 Hatle L, Angelson B. Doppler ultrasound in cardiology; physical principles and clinical application, 2nd ed. Philadelphia: Lea \& Febiger, 1985:115-9.

13 Currie PJ, Seward JB, Chan K, et al. Continuous wave Doppler determination of right ventricular systolic pressure. A simultaneous Doppler catheterization study in 127 patients. J Am Coll Cardiol 1985;6:750-6.

14 Wilkins GT, Weyman AE, Abascal VM, et al. Percutaneous mitral valvotomy: an analysis of echocardiographic variables related to outcome and mechanism of dilatation. Br Heart J 1988;60:299-308.

15 Inoue K, Owaki T, Nakamura T, et al. Clinical applications of transvenous mitral commisurotomy by a new balloon catheter. J Thorac Cardiovasc Surg 1984:87:394-402.

16 Fawzy ME, Mimic L, Savanna V, et al. Advantage of Inoue balloon catheter in mitral valvotomy: experience with 220 consecutive patients. Cathet Cardiovasc Diag 1996;38:9-14.

17 Chen CR, Cheng TO. Percutaneous balloon mitral valvuloplasty by the Inove technique: a multicenter study of 4832 patients in China. Am Heart J 1995; 129:1197-203.

18 Hermann HC, Romaswamy K, Isner JM, et al. Factors influencing immediate results, complications, and short-term follow-up results after Inoue balloon mitral valvotomy: North American multicenter study. Am Heart $J$ 1992;124:160-62.

19 Cohen DJ, Kuntz RE, Gordon SP, et al. Predictors of long-term outcome after percutaneous mitral valvuloplasty. N Engl J Med 1992;327:1329-35.
20 Palacios IF, Tuzcu ME, Weyman AE, et al. Clinical follow up of patients undergoing percutaneous mitral balloon valvotomy. Circulation 1995;91:671-6.

21 lung B, Gabarz E, Michaud P, et al. Late results of percutaneous mitral commissurotomy in a series of 1024 patients. Analysis of late clinical deterioration: frequency, anatomic findings, and predictive factors, Circulation 1999;99:3272-8.

22 Hamasaki N, Nosaka H, Kimura T, et al. Ten years clinical follow-up following successful percutaneous transvenous mitral commissurotomy. Catheterization and Cardiovascular Interventions 2000;49:284-8.

23 Wang A, Krasuski RA, Warner JJ. Serial echocardiographic evaluation of restenosis after successful percutaneous mitral commissurotomy. J Am Coll Cardiol 2002;39:328-34.

24 Shrivastava S, Tandon R. Severity of rheumatic mitral stenosis in children. Int J Cardiol 1991;30:163-7.

25 Dev V, Shrivastava S. Time course of changes in pulmonary vascular resistance on mechanism of regression of pulmonary artery hypertension after balloon mitral valvuloplasty. Am J Cardiol 1991;67:439-42.

26 Fawzy ME, Mimish L, Sivanandam V, et al. Immediate and long-term effect of mitral balloon valvotomy on severe pulmonary hypertension in patients with mitral stenosis. Am Heart J 1996;131:89-93.

27 Casale $\mathrm{P}, \mathrm{Block} \mathrm{PC}, \mathrm{O}^{\prime}$ Shea J, et al. Atrial septal defect after percutaneous mitral balloon valvuloplasty: immediate results on follow-up. J Am Coll Cardiol 1990; 15:1300-4.

28 Ishikura F, Nagata S, Yasuda S, et al. Residual atrial septal perforation after percutaneous transvenous mitral commissurotomy with Inoue balloon catheter. Am Heart J 1990;120:873-8.

29 Cequier A, Bonan R, Sella A, et al. Left to right shunting after percutaneous mitral valvuloplasty: Incidence and long-term hemodynamic follow-up. Circulation 1990;81:1190-7.

\section{IMAGES IN CARDIOLOGY}

\section{Right ventricular outflow tract obstruction in an infant}

A 3 month old, asymptomatic infant with tuberous sclerosis and multiple intracardiac tumours that were diagnosed prenatally (panel A) underwent surgery for resection of a large tumour $(1.3 \times 0.8 \times 0.7 \mathrm{~cm})$ obstructing the right ventricular outflow tract (RVOT) (panel B). After birth the infant was followed expectantly given that the natural history of these tumours is often spontaneous regression. However, the peak gradient across the RVOT increased steadily from $40 \mathrm{~mm} \mathrm{Hg}$ to $100 \mathrm{~mm} \mathrm{Hg}$, prompting surgery to relieve the obstruction and break the cycle of stenosis begets hypertrophy begets stenosis. The large size of the tumour necessitated a right ventriculotomy (panel C). Histology confirmed the diagnosis of rhabdomyoma (panel D). Recovery from surgery was uneventful. The RVOT remained patent with a residual gradient of $34 \mathrm{~mm} \mathrm{Hg}$ as measured by echo Doppler.

M Friedberg

$\mathrm{N} H$ Silverman mark.friedberg@stanford.edu
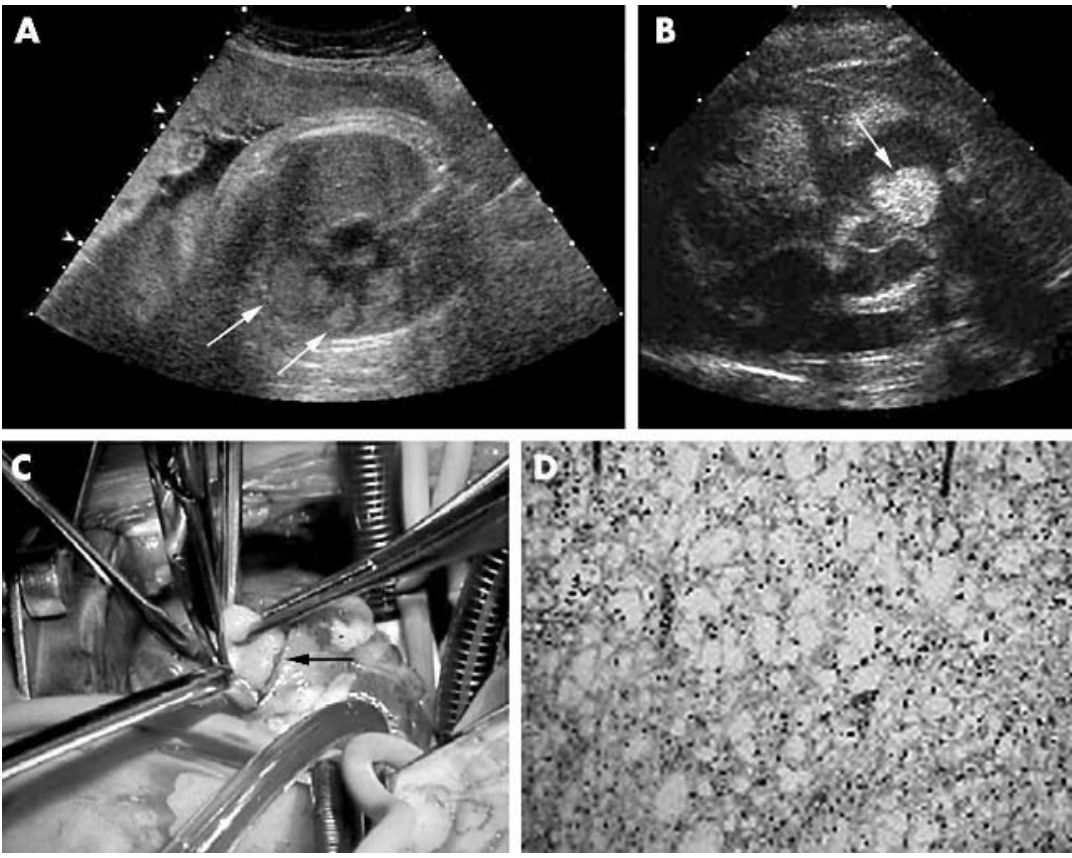

(A) Fetal echocardiogram, four chamber view, demonstrating multiple rhabdomyomas in the left and right ventricles (arrows). (B) Transthoracic parasternal short axis view. There is a large rhabdomyoma (arrow) causing obstruction of the right ventricular oufflow tract. The tumour is situated immediately proximal to the pulmonary valve. Additional tumours are seen proximally in the right ventricle. (C) Intraoperative photograph. The tumour (arrow) demonstrated in panel B is excised through a right ventriculotomy. (D) Histology confirming the diagnosis of rhabdomyoma. Haematoxylin \& eosin staining. 